\title{
Pasture development revisited: A model to analyse the physical and financial risk of developing pastures on sheep and beef cattle farms
}

\author{
J.A. MARTINS da SILVA ${ }^{1}$, W.J. PARKER, N.M. SHADBOLT and C.K. DAKE \\ Department of Agribusiness \& Resource Management, Massey University, Palmerston North
}

\begin{abstract}
In order to assist pastoral farmers determine whether investment in pasture development is worthwhile, a spreadsheet model was developed to analyse its effect on farm production and profit. The model incorporates a feed budget that accounts for the proportional impact of pasture development on the seasonality, quality and total supply of feed, and this is utilised to support additional livestock. The impact of pasture development on costs and revenue are accounted for in a yearly cash flow template because cash balances over the development period are a measure of feasibility. The effect of climatic conditions on pasture production, and hence livestock performance and sales, and of variation in future product prices were analysed for two case farms: one in New Zealand and the other in southern Brazil. The results, presented in terms of a probability distribution of the net present value (NPV) of the net profit after tax and before interest (NOPAT) for the pasture development programmes, provide a farmer with more insight into the physical and financial consequences of pasture development than an analysis based on current average costs and prices.
\end{abstract}

Keywords: investment analysis, pasture development, profitability, risk, spreadsheet model

\section{Introduction}

Farm development through expansion or intensification of pasture production provides a potential mechanism for pastoral farmers to increase the profitability of their business in the face of declining real returns. The decision to develop a farm, or part thereof, involves both production and price uncertainty. When this is superimposed on a planning horizon of 5-20 years the farmer confronts a challenging decision problem. Furthermore, farm development in New Zealand and in many other countries must now proceed without Government subsidies, and because of this, it has

1 Current address: Av. Sete de Setembro, 1246, Bage-R.S., CEP 96.400 become more important to formally account for the risk associated with farm development (Martin 1994). There is a need therefore, in this new economic environment, to revisit the question of whether farm development, which frequently involves pasture improvement, is profitable. The increased power and flexibility of computers can assist in this task because they allow the routine application of proven techniques for analysing the "riskiness" of development options. The output from a risk analysis provides farmers with a richer picture of the likely outcomes for different development scenarios than an analysis based on average or conservative values. While experienced consultants or farmers may have a good sense of the range of possible outcomes from development, it is difficult for them to quantify or estimate the relative importance of the variables contributing to this, particularly when responses to inputs occur over several years.

This paper describes a spreadsheet model which integrates pasture development with beef cattle production and assesses the effects of this on overall farm business performance. The model's application is illustrated in relation to two case farms with beef cattle: one in the lower North Island of New Zealand and the other in southern Brazil. In both countries, land development must now be carried out entirely within the resources available to the farmer, who consequently must also bear all the risk.

\section{Model design}

A spreadsheet model with a stochastic capability was developed with the Excel and @ Risk software packages to represent pasture supply and demand, and income and expenditure for the whole farm system (Figure 1). A full description of the model's formulation and operation is presented in Martins da Silva et al. (1997) and only a brief outline is provided here.

To describe the effects of development, the model reconciles livestock numbers and their production with the forecasted changes in pasture supply and quality associated with pasture improvement. Inputs to describe pasture development are illustrated in Table 1. Extra animals can be carried as a result of improved monthly growth (kg DM/ha/day) from new pasture species (and 
Figure 1 An overview of the relationship between the components of the farm development model.

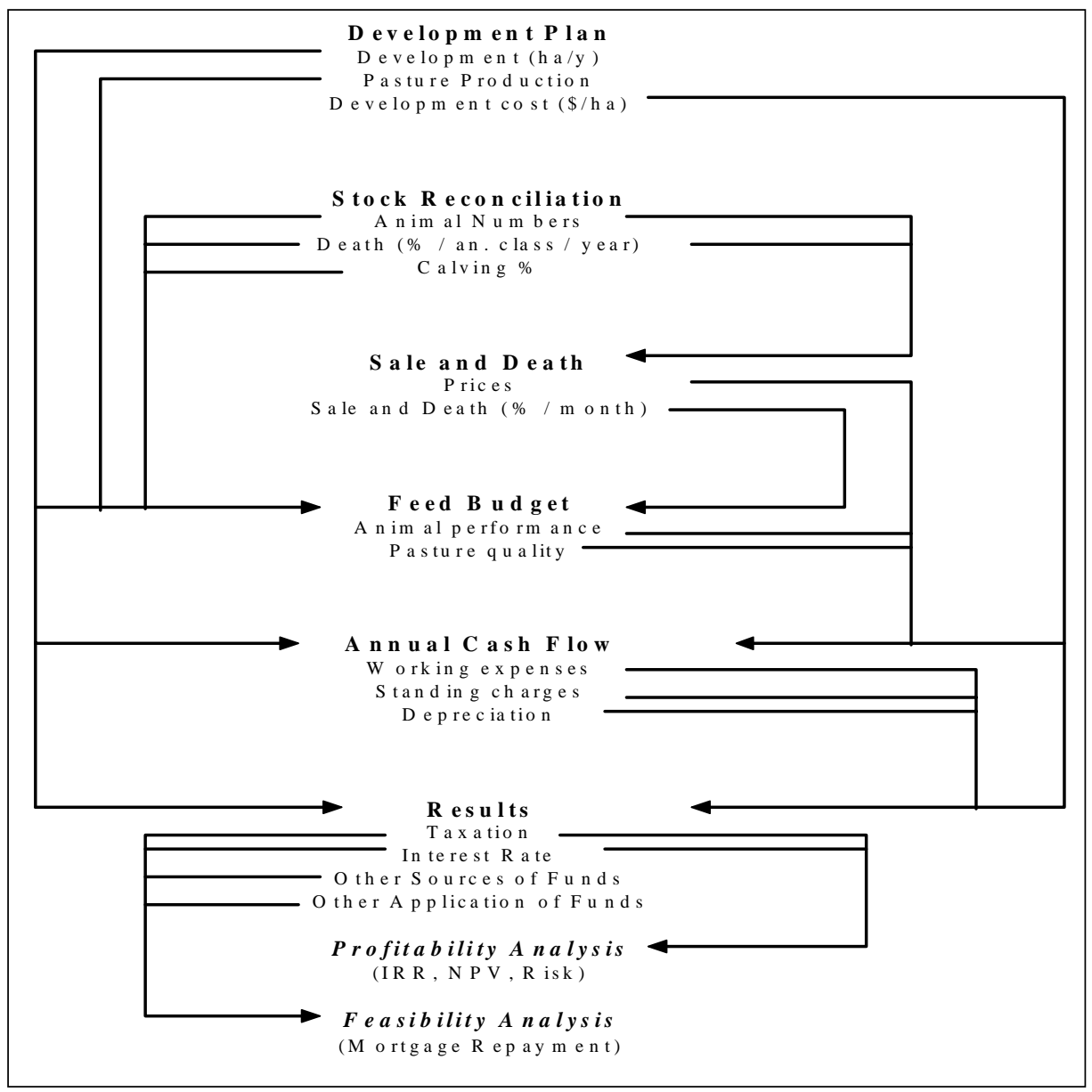

Table 1 Template for inputting details about pasture development. Note that a new pasture does not reach its production potential until year 3 .

\begin{tabular}{|c|c|c|c|c|c|c|}
\hline \multicolumn{7}{|l|}{ Development Plan } \\
\hline \multirow[b]{2}{*}{ Crop Area } & \multirow[b]{2}{*}{0} & & Native & New & & \\
\hline & & & Pasture & Pasture & & \\
\hline New Pasture Area (ha/y) & $\overline{0}$ & & \multicolumn{4}{|c|}{ Production Production (kgDM/ha/d) } \\
\hline Native Pasture Area (ha) & 1157 & Month & Actual & Year 1 & Year 2 & Improved \\
\hline \multirow[t]{2}{*}{ Development Cost (\$/ha) } & \multirow[t]{2}{*}{838} & Jul & 10 & \begin{tabular}{|r|}
10 \\
\end{tabular} & 21 & \begin{tabular}{|l}
21 \\
\end{tabular} \\
\hline & & Aug & 13 & 12 & 32 & 32 \\
\hline Pasture in Year 1(ha) & 7 & Sep & 21 & 21 & 40 & 54 \\
\hline Pasture in Year 2 (ha) & 41 & Oct & 31 & 31 & 45 & 56 \\
\hline \multirow[t]{2}{*}{ Improved Pasture (ha) } & \multirow[t]{2}{*}{1049} & Nov & 35 & 35 & 60 & 60 \\
\hline & & Dec & 31 & 31 & 55 & 56 \\
\hline \multirow[t]{2}{*}{ Total Pasture area (ha) } & \multirow[t]{2}{*}{2255} & Jan & 19 & 12 & 39 & 38 \\
\hline & & Feb & 16 & 0 & 5 & 39 \\
\hline \multirow[t]{3}{*}{ Stocking Rate increase } & \multirow[t]{3}{*}{$0.00 \%$} & Mar & 25 & 0 & 13 & 50 \\
\hline & & Apr & 23 & 32 & 32 & 49 \\
\hline & & May & 16 & 24 & 24 & 35 \\
\hline \multirow[t]{2}{*}{ Total Project NPV } & \multirow[t]{2}{*}{0} & Jun & 11 & 15 & 16 & 24 \\
\hline & & Total (kgDM & 7643 & 6822 & 11863 & 15647 \\
\hline Pasture to develop (ha) & 247 & & & & & \\
\hline
\end{tabular}


associated additional fertiliser inputs) and the higher quality (MJ ME/kg DM) of the developed vs. undeveloped pastures. The total metabolisable energy available to animals is therefore the average monthly weighted (by the proportion of the effective grazing area) pasture production and quality for the farm. The way animals (in this case cattle) utilise pasture is a function of the monthly stock reconciliation and the specified levels of animal performance (i.e., animal intake is the sum of the requirements for animals across classes). The feasible rates of liveweight change are determined iteratively from the pattern of monthly pasture cover, using the same principles as in STOCKPOL (Marshall et al. 1991). Changes in farm inputs for pasture development and running expenses and outputs are accounted for in terms of their cost and effect on farm revenue. The annual net cash balances (or NOPAT; net operating profit after tax and before interest) for the defined development budget (e.g., 1996 to 2020) are discounted to derive the net present value (NPV) of the development programme (Figure 1). The NPV indicates the profitability of development at today's values and includes the capitalised NOPAT earnings stream (i.e., salvage value) beyond the specified development period. The feasibility of a project is also evaluated through time with respect to the farm's debt situation and ability to meet normal expenses. In essence, the feasibility analysis provides an overview of the farm's predicted financial position during each year of development in terms of the need for, and the ability to service, extra borrowing. It complements the profitability analysis, because a positive NPV (a criterion for proceeding with development) does not necessarily mean that a development programme is feasible.

The risks associated with pasture production and beef prices were considered because both have a large influence on the physical outputs and the profitability of farm development. Production risk is estimated indirectly from the monthly variation in district rainfall (a proxy variable for pasture production) across years. The probability of a particular pattern of rainfall can be either derived from local records or estimated subjectively by the farmer. Pasture production estimates reflect the variation in rainfall in the current year as well as carry-over effects due to the pattern of rainfall in the previous year (e.g., damage to pastures because of drought). Price risk was estimated by fitting monthly schedule prices from 1980-1996 for steers in a midcarcass weight range to a Fourier curve. This allowed cyclic changes in beef schedule prices to be forecasted for the development period and incorporated into the expected income. This contrasts with the usual method of using a single average (often the current) price for budget projections.

\section{Model application to case farms}

The model was used to simulate pasture development on the case farms, located in the lower North Island of New Zealand and southern Brazil, near the city of Bage in Rio Grande do Sul, respectively. Both farms already had some pastures under development (Table 2) but the owners were questioning whether further development should proceed. Financial and physical data were obtained for the 1995/96 season and verified in close consultation with the farmers.

Table 2 Summary of pasture, livestock and financial characteristics of the two case farms in 1995/96 and after development.

\begin{tabular}{|c|c|c|c|c|}
\hline \multirow[t]{2}{*}{ Parameter } & \multicolumn{2}{|c|}{ New Zealand } & \multicolumn{2}{|c|}{ Brazil } \\
\hline & $1995 / 96$ & Post-dvlpmt & $1995 / 96$ & Post-dvlpmt \\
\hline Total area & 2598 & 2598 & 6060 & 6060 \\
\hline \multicolumn{5}{|l|}{ Pastures } \\
\hline - Undeveloped & 1157 & 910 & 2609 & 346 \\
\hline - Under development & 49 & - & 760 & - \\
\hline - Developed & 1049 & 1345 & 972 & 3995 \\
\hline \multicolumn{5}{|l|}{ Livestock } \\
\hline - R1 \& 2yr hfrs & 371 & 442 & 1062 & 1634 \\
\hline - Bdg cows & 665 & 792 & 1263 & 1945 \\
\hline - Steers & 988 & 1177 & 645 & 993 \\
\hline - Bulls & 19 & 23 & 388 & 598 \\
\hline - Total cattle & 2043 & 2434 & 3358 & 5170 \\
\hline - Total sheep & 10126 & 10126 & 1220 & 1220 \\
\hline - Total horses & - & - & 208 & 208 \\
\hline \multicolumn{5}{|l|}{ Financial (\$/eff ha) } \\
\hline - Gross farm revenue & 376.72 & $398.23^{1}$ & 181.46 & $237.27^{2}$ \\
\hline - Farm cash expend. & 362.53 & 374.72 & 135.59 & 145.36 \\
\hline - Cash surplus & 14.19 & 23.50 & 45.87 & 91.91 \\
\hline - Debt & 776.05 & 1305.00 & 27.18 & 253.40 \\
\hline
\end{tabular}

In the modelling analysis the profitability and feasibility of continuing the status quo (1995/96 season; Table 2) was compared with two rates of pasture development for each farm. Extra pasture production was used solely to increase beef cattle numbers at their current levels of performance. This simplified the analysis, but also the Brazilian farm had few sheep and the New Zealand farmers' preference was to increase the beef herd. The rates of development for the New Zealand farm were 25 and $50 \mathrm{ha} /$ year to a total of $247 \mathrm{ha}$, while those for the Brazilian farm were 250 and 500 ha/year to a total of 2263 ha. The respective costs for establishing new pastures on the case farms are shown in Table 3. Price and production variation was introduced and the probability distribution of NPVs for the different options compared in terms of stochastic dominance. 
Table 3 Pasture development costs (1996 \$NZ/ha) for the two case farms.

\begin{tabular}{lcc}
\hline Item & New Zealand & Southern Brazil \\
\hline Cultivation & 189 & 110 \\
Fertiliser (material \& application) & 305 & 140 \\
Seed \& sowing & 242 & 133 \\
Freight & 44 & 29 \\
Weed control & 56 & - \\
Total & $\mathbf{\$ 8 3 6}$ & $\mathbf{\$ 4 1 2}$ \\
\hline
\end{tabular}

\section{Results and discussion}

The model simulations for the New Zealand case farm showed that developing 247 ha of reverted pasture into improved pasture would be profitable at a $6 \%$ post-tax discount rate as shown by the probability of financial gains from the two rates of development (50 ha/year and $25 \mathrm{ha} /$ year) in Figure 2. The 50 ha/year scenario is shown to have first degree stochastic dominance over the two other options at a $6 \%$ discount rate (i.e., the curve lies independently and to the right of the other two curves). The payback period (PP) for the $25 \mathrm{ha}$ /year option was 19 years, while that for the 50 ha/year programme was 18 years. The major restriction to pasture development was the need to borrow funds for development when beef cattle returns were projected to be low from 1997-1999.

In contrast, developing the 2263 ha of native pasture into improved pasture on the Brazilian farm was not profitable by 2020 at a $16 \%$ discount rate when production and price risk were incorporated in the analysis (Figure 3). Losses were greater for developing $500 \mathrm{ha} /$ year than $200 \mathrm{ha} /$ year and there was more than a $90 \%$ chance that this rapid rate of development would have a negative NOPAT. The status quo situation had first degree stochastic dominance over both rates of development at a $16 \%$ discount rate.

A discount rate of $6 \%$ was also used to evaluate the development options on the Brazilian farm because interest rates are likely to fall over the next few years as the economy recovers. At this discount rate, pasture development at both rates would be profitable, as illustrated in Figure 4 by the positive NPVs for their probability distribution curves. In contrast to the $16 \%$ discount rate scenario, the 500 ha/year project had first degree stochastic dominance over both the $200 \mathrm{ha} /$ year and status quo options.

\section{Conclusions}

Farmers are required to make investment decisions on the basis of imperfect knowledge. Some of these decisions, such as a commitment of expenditure to pasture development, are not able to be reversed without significant monetary loss. It is therefore important to carefully analyse the likely animal production and financial consequences of growing extra and better quality pasture. The farm development model, described in this paper, generates objective information for the farmer/consultant on the likely outcomes from

Figure 2 The probability of NPVs for the New Zealand case farm at a $6 \%$ discount rate. The status quo (SQ) line, for example, indicates a $55 \%$ chance of earning a NOPAT of at least NZ $\$ 100,000$. An option to the right of another is preferable and has first degree stochastic dominance.

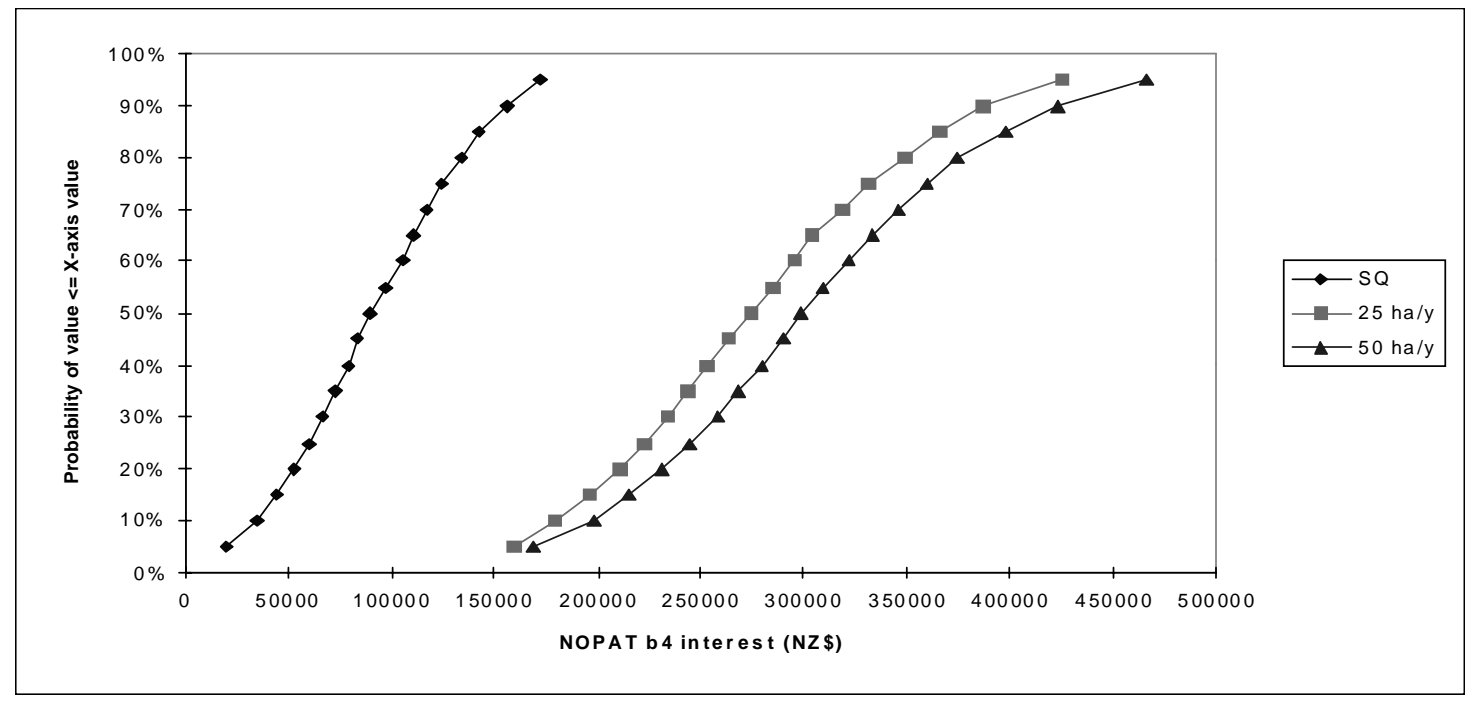


Figure 3 Probability of NPVs for the Brazilian case farm at a $16 \%$ discount rate.

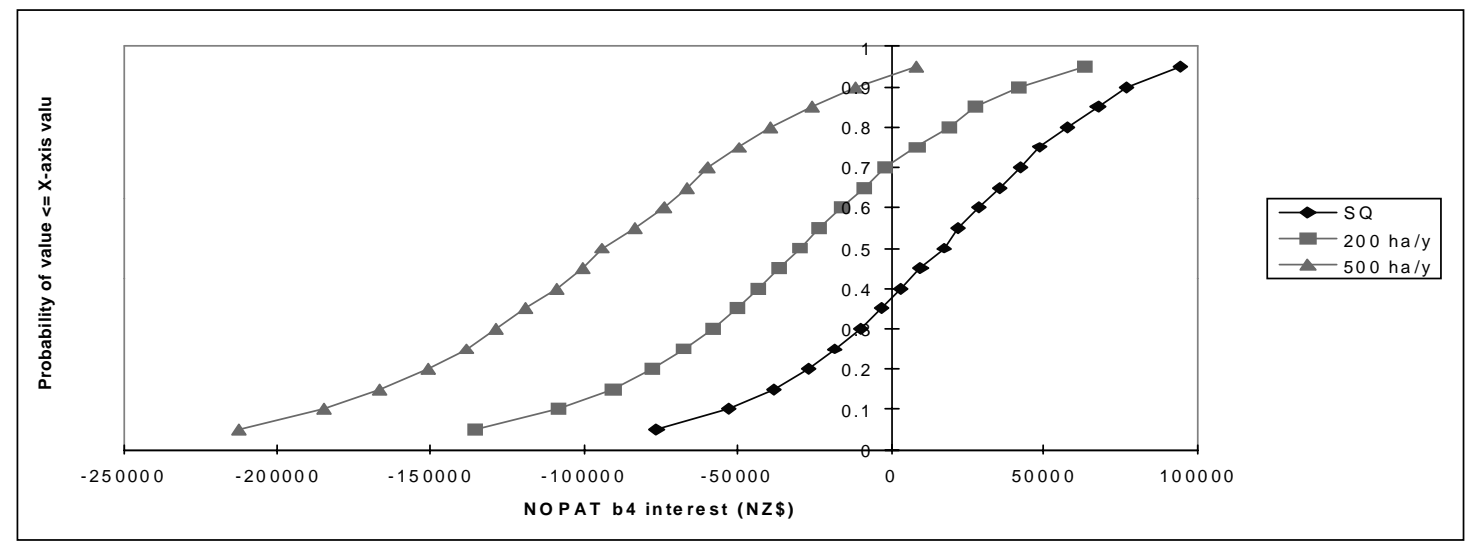

Figure 4 Probability of the NPVs for the Brazilian case farm at a $6 \%$ discount rate.

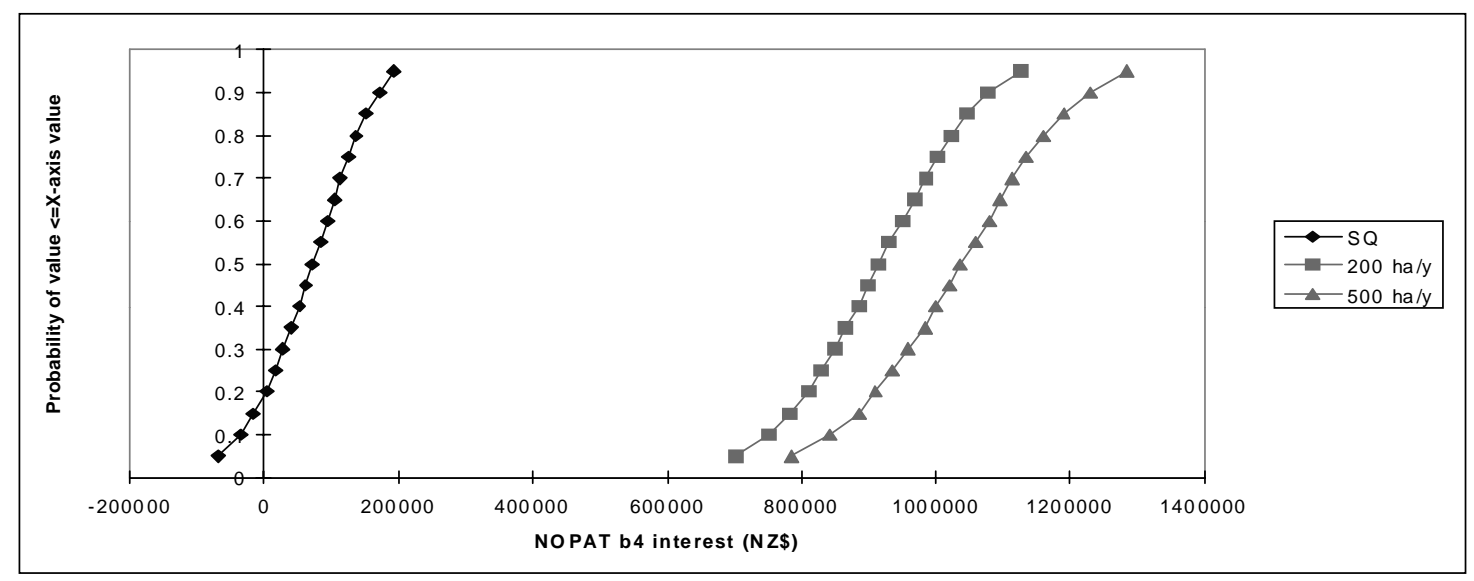

improving pasture. The model integrates pasture supply, livestock numbers and income and expenditure to provide the annual cashflow for alternative development options. Historically development budgeting has focused mostly on projected income and expenditure relative to a subjective assessment of changes in feed supply and livestock numbers. The model enables different rates and types of pasture development to be analysed quickly and the effect of variable weather and fluctuating future prices on the farm's cash flow to be estimated. Consequently, the sensitivity of the results to changes in the cost of capital and prices can be quantified. This provides the farmer with a more complete picture of the benefits and risks of pasture development than forecasts based solely on current average values.

\section{ACKNOWLEDGEMENTS}

This work was partially funded by the New Zealand Ministry of Foreign Affairs and Trade and the New Zealand Agricultural and Resource Economics Society. Thanks are due to David Pearce (New Zealand) and João Carlos Martins da Silva (Brazil) for providing farm data for the study.

\section{REFERENCES}

Marshall, P.R.; McCall, D.G.; Johns, K.L. 1991. Stockpol: A decision support model for livestock farms. Proceedings of the New Zealand Grassland Association 53: 137-140.

Martin, S.K. 1994. Risk perceptions and management response to risk in pastoral farming in New Zealand. 
Proceedings of the New Zealand Society of Animal Production 54: 363-368.

Martins da Silva, J.A.G.; Parker, W.J.; Shadbolt, N.M.; Dake, C. 1997. A stochastic spreadsheet model for analysing investment options for the development of pasture on beef cattle farms. Proceedings of the New Zealand Agricultural and Resource Economics Society, AERU Discussion Paper No. 145: 202208. 